\title{
Research on the Performance and Trust Status Parties in Contract Services of Family Doctors in the Suburbs of Beijing
}

\section{Yingchun Peng ( $\sim$ pycjql@ccmu.edu.cn )}

Capital Medical University School https://orcid.org/0000-0001-8867-9190

Jiaojiao Zhou

Capital Medical University School

\section{Zhiying Zhang}

Capital Medical University School

\section{Ruyi Zhang}

Capital Medical University School

\section{Ludan Lv}

Capital Medical University School

\section{Zhe Wang}

Capital Medical University School

\section{Jingjing Cheng}

Capital Medical University School

\section{Research article}

Keywords: family doctor contract service, doctor-patient mutual trust, suburbs of Beijing

Posted Date: December 22nd, 2020

DOl: https://doi.org/10.21203/rs.3.rs-131589/v1

License: (9) (i) This work is licensed under a Creative Commons Attribution 4.0 International License. Read Full License 


\section{Abstract}

Background: Family doctor contract service is an important instrument to carry out the hierarchical medical system in China. As the capital of China, Beijing's family doctor contract services are leading the country. This study aims to research the status of family doctor contract services in the suburbs of Beijing, the contract awareness, the degree of trust and the emerging ethical problems between doctors and patients, so as to evaluate the influences of the contract awareness and trust degree of the contract parties on the subjects' renewal intention. We expect to explore the feasible ways to solve the obstacle to building doctor-patient mutual trust in family doctor contract services in the suburbs of Beijing.

Methods: First, the members of the research team analyzed the statistical data on the services contracted by family doctors. Then, we applied the multi-stage stratified random sampling method to chose a sample of 202 medical staff in the family doctor teams and 197 residents from 4 suburb areas in Beijing. A semi-structured individual in-depth interview method was used to conduct face-to-face interview with 36 medical staff in the family doctor teams.

Results: The number of teams and personnel contracted by family doctors has increased year by year, and the resident contracting rate has slowly increased since then a decline in 2015. In 2018, the contracting rate of residents dropped. In that year, the average contracting rate for family doctor services in Beijing was $33.86 \%$. The self-evaluation of the contracted residents on the family-doctor signing service system shows that only 68 (34.5\%) contracted residents know a lot about it, while 11 (5.6\%) signed residents said they did not understand the system at all. Thirty-two percent of the medical staff surveryed by the questionnaire said the attributes of the relationships between the two parties was a trust relationship, but $50.5 \%$ of the medical staff and $68.0 \%$ of the contacted residents still said that the nature of both parties just was a relationship of diagnosis and treatment. In addition, only $16.3 \%$ of the contracted residents are active in performing the contract, and $2 \%$ of the signed are very active. From the perspective of medical staff in family doctor teams, the contracting residents' trust in family doctors' contracting services and medical staff is underestimated. Moreover, for maintaining a long-term and stable contracting service relationship, the willingness of the residents is significantly higher than that of family doctors in providing such services.

Conclusions: This study evaluates the status of contract awareness, the mutual trust between doctors and patients, and the willingness to renew the contracts. It also points out that the family doctor contracting service system hinders the construction of doctor-patient mutual trust. The governments and relevant medical institutions should respect the choices of the residents to enter such contracts at their proper times and places. Meanwhile, they should reasonably define and standardize the content of family doctor contracting service programs to improve the sense of gain of both parties. Futhermore, relevant organizations should take practicable measures to address the lack of staff in the family doctor teams, reduce the nonmedical workload of medical staff, and ensure the implementation of the services contracted family doctors, and draft effective incentives to improve the initiatives of both parties. 


\section{Background}

In the 1980s, the concept of general practitioners was introduced in China, and the family doctor system has gradually developed fast since then[1]. It was a primary goal of the reform of the medical and health care system that everyone could realize the accessibility to basic medical and health services, pointed out by the Opinions of the CPC Central Committee and the State Council on Deepening the Reform of the Medical and Health Care System on March 17, 2009. [2]. Afterwards, in the development of communitybased health services in Beijing, Shanghai, Wuhan and other cities in China, had put forward the idea of "family doctor" services successively [3].Beijing, as one of the first pilot areas of family doctor contracting service systems in China, began to providing family doctor contracting services since 2010. And in 2011, there were 1.485 million-contracts signed in Beijing, reaching it's peak in 2014, with 9.245 million contracts signed. Later, under the program of "improving quality and reducing weight", Beijing paid attention to raising the contract quality and gradually expanded key groups under such contracts[4]. In 2017 , the number of contracting residents in the city reached 8.654 million[5].Then in 2018, due to fulfilling policy of population demobilization, Beijing's floating population was decreased, and so was the number of it's family doctors dropped accordingly. The number of the city's contracting reached $7,294,100$, with a head benefit of 8.45 times each person [6].

As the capital of China, Beijing is equipped with unique medical resources, and its community-based community health services also take the lead in the country. In 2018, 336 community health service centers and 1586 community health service stations had performed in a normal model in the 16 Districts of Beijing. The community-based health services had 37464 staffers, 31163 of whom are health technicians. The number of consultations and treatments in community health service organizations in the city reached 65.691 million, and the number of people served by family doctors was 61.648 million [6]. However, such problems as insufficiency in the supply capacities of primary medical and health service institutions, the number of family doctors and the strength of supporting policies caused a big gap between the provision of family doctor contracting services and the expectation of residents. The lack of contract formations for family doctor contracting services is often criticized by residents. So it is difficult to preserve the mutual trust between family doctor service teams and residents.

The existing researches mainly focus on trust between doctors and patients, but discussing institutional trust is limited to the theoretical level. Still, most researches pay litter attention to doctor-patient trusts in suburban area. There are specific geographical environments, population composition, environmental supports (including network, communication and transportation), and other conditions in the suburbs of Beijing. In fact, the trust between doctors and patients for such services in the suburban areas is special. Therefore, it is necessary to carry out this research to explore related.

China is at a stage of deep reform the medical and health care system while developing it health care. The mountainous region of Beijing cover an area of 10,200 square kilometers, accounting for about $62 \%$ of the total. Meanwhile, the population density in the suburbs of Beijing is smaller than that in the urban area, so the medical resources in the suburbs are much scarcer than in the core areas of urban [7]. In 
other words, the radius of medical services in the suburbs of Beijing is large. In 2018, the service radius of community health service centers in the mid-mountainous region of Beijing and suburban plains were $12.4 \mathrm{~km}$ and $4.8 \mathrm{~km}$, respectively. In contrast, the radius of community health service centers in Beijing's urban plains was only $2.3 \mathrm{~km}$. he average service radius of Mentougou District, Huairou District, and Miyun District all exceeded 12 kilometers [6]. It is an ideal case to study the doctor-patient problems arising from signing a family doctor's contract service.

\section{Methods}

\section{Data Collection and Measures}

This study used multi-stage stratified random sampling method. In the first stage. Two areas each with a family doctor's contract service benefiting above and below Beijing's average level were selected in Beijing. They are Mentougou District, Miyun District, Huairou District and Daxing district. In the second stage, we selected about 1/3 1/4 of the townships in layers in each selected area. Finally, according to the contract files of family doctors proved by community institutions, randomly select the contracted residents at the selected township community health service centers as the questionnaire survey objects. Meanwhile, 50\% 60\% medical staff who have joined the family doctor service team are also chosen as questionnaire respondents. One general practitioners, one nurse and one preventive health care personnel were randomly selected to in the in-depth individual interview. Inclusion criteria for residents: (1) permanent residents within the jurisdiction; (2) residents who have signed the "family doctor signing service agreement" with community health service agencies. Inclusion criteria for medical staff:Community health workers who join the family doctor service team and provide family doctor contracting services.

The research team found out a rigorous review and oversight procedures to ensure the quality of the investigation. All respondents were guaranteed the right to remain anonymous and refuse to join during interviews and analyses. The Ethics Committee of Capital Medical University approved this study. At the beginning of the interview, each subject received informed consent. After the interview, each survey participant in this study obtained informed consent. After the interview, each subject received a survey gift.

In this study, from July to September 2017, a group of trained investigators conducted structured questionnaires and semi-structured personal in-depth interviews in 4 regions selected in Beijing. Two hundred and two family doctor team medical staff and 197 residents engaged in the questionnaire survey, and 36 family doctor team medical staff joined in the in-depth individual interview. Questionnaire survey questions include the socio-demographic characteristics of the contracting parties, the cognition of the family doctor contracting service system the attributes of doctor-patient relationship. And the compliance behavior and initiative of both parties. From the perspective of the contracting parties, the level of trust and interpersonal trust of residents in the contracting services of family doctors, and the willingness of the contracting parties to continue to sign contracts, etc. Personal in-depth interview 
questions include evaluating the performance of the contracted residents by the medical staff of the family doctor team and evaluating residents' institutional and interpersonal trust in family doctor contract service.

Preparing the questionnaire is divided into three steps: Firstly, literature research had generated the items of questionnaire. Secondly, we used a formal consensus process based on nominal group technology (NGT) to evaluate it[9]. After completed the questionaire, we conducted a preliminary survey on 50 medical staff members of the family doctor team and 50 contracted residents in Mentougou and Huairou Districts. The internal consistency reliability (Cronbach's a) of the signed residents questionnaire was 0.802 , and the internal consistency reliability (Cronbach's a) of the medical staff questionnaire was 0.831 . At the same time, the surface validity and content validity of the questionnaire are verified by health statistics experts and health professionals. The results showed the questionnaire had good reliability and validity.

Compiling the interview outline is divided into two steps: Firstly, the existing research results were reviewed and the preliminary outline was made under the guidance of health management and medical ethics experts. Secondly, we use this outline to conduct pre-interviews with the 3 family doctor team medical staff. After discussing the interview results and the interviewee's feedback with experts, the interview outline was further revised and improved to form the final interview outline.

\section{Statistical Analysis}

We set up the questionnaire survey by using Epidata 3.1 software to gain the data, and we calculate the mean value of measurement by using SPSS 19.0. The count data was analyzed for composition ratio, frequency description, and ranking. We compared and analyzed the data of the two groups, and $P<0.05$ was considered statistically significant. Also, we adopted the thematic frame analysis method for the texts of personal in-depth interview, the core of which is to settle "thematic framework". It mainly includes two major steps of data collation (including fixing the subject framework, data labeling and classification) and analysis. Ensure the integrity and transparency of data processing and analysis.

\section{Results}

\section{Socio-demographic characteristics of the respondents}

In this study, 216 medical staff members of family doctors were included in the research questionnaire. Incomplete data were eliminated, 202 valid respondents (effective recovery rate was $94.4 \%$ ).

Among the medical staff interviewed, $25.2 \%$ are practicing in Huairou District, $24.4 \%$ in Miyun District, $25.2 \%$ in Daxing district, and 25.2\% in Mentougou District., with an average age of 35.0 \pm 8.9 years. Thirty five point six percent of medical staff engaged in general medical posts, $17.8 \%$ are in nursing posts, $15.8 \%$ engaged in defense Insurance position, and of medical personnel engaged in rehabilitation, management, traditional Chinese medicine, pharmacy, oral cavity and other posts. 
Table2 The social demography characteristics of family doctors in suburban Beijing $\llbracket n=202 \rrbracket$

\begin{tabular}{|lll|}
\hline Variable & $\mathrm{n}$ & $\%$ \\
\hline Gender & & \\
\hline Female & 51 & 25.2 \\
\hline Male & 151 & 74.8 \\
\hline Age(years) & & \\
\hline$\leq 44$ & 167 & 82.7 \\
\hline $45 \sim 59$ & 32 & 15.8 \\
\hline$\geq 60$ & 3 & 1.5 \\
\hline Education & & \\
\hline Senior high school and below & 15 & 7.4 \\
\hline Junior college & 60 & 29.7 \\
\hline Bachelor degree or above & 127 & 62.9 \\
\hline Post & & \\
\hline General practitioner & 72 & 35.6 \\
\hline Nurse & 36 & 17.8 \\
\hline Preventive health care worker & 32 & 15.9 \\
\hline Others & 62 & 30.7 \\
\hline District & 51 & 25.2 \\
\hline Huairou District & 51 & 24.4 \\
\hline Miyun District & 51.2 \\
\hline Daxing district & 51.2 \\
\hline Mentougou District & & \\
\hline
\end{tabular}

A total of 216 contracted residents were included, and incomplete data were excluded. Effective respondents were 197 (effective recovery rate $91.2 \%$ ). Among them, $25.9 \%$ of the contracted residents lived in Huairou District, 24.4\% lived in Miyun District, 23.8\% lived in Daxing district, and $25.9 \%$ lived in Mentougou district. Among the 197 participants, the youngest was 20 years old and the oldest was 83 years old, with an average age of $58.0 \pm 12.9$ years. $44.7 \%$ of the residents were less than 15 minutes away from the nearest community health service center, $25.4 \%$ of residents need 15 to 30 minutes, $29.9 \%$ 
of residents need more than 30 minutes to go to the community health service center for medical treatment.

Table2 The social demography characteristics of contracted residents in Beijing suburbs $\llbracket n=197 \rrbracket$ 


\begin{tabular}{|c|c|c|}
\hline Variable & $\mathrm{n}$ & $\%$ \\
\hline \multicolumn{3}{|l|}{ Gender } \\
\hline Female & 55 & 27.9 \\
\hline Male & 142 & 72.1 \\
\hline \multicolumn{3}{|l|}{ Age(years) } \\
\hline$\leq 44$ & 27 & 13.7 \\
\hline $45 \sim 59$ & 67 & 34.0 \\
\hline $60 \sim 74$ & 92 & 46.7 \\
\hline 75 89 & 11 & 5.6 \\
\hline \multicolumn{3}{|l|}{ Education } \\
\hline Primary and below & 66 & 33.5 \\
\hline Junior high school & 86 & 43.6 \\
\hline High school & 25 & 12.7 \\
\hline College & 12 & 6.1 \\
\hline Bachelor degree or above & 8 & 4.1 \\
\hline \multicolumn{3}{|c|}{ The time required for a medical journey } \\
\hline$\leq 15 \mathrm{~min}$ & 88 & 44.7 \\
\hline 15 30min & 50 & 25.4 \\
\hline$\geq 30 \mathrm{~min}$ & 59 & 29.9 \\
\hline \multicolumn{3}{|c|}{ Treatment frequency (times/year) } \\
\hline 0 & 11 & 5.6 \\
\hline $1-2$ & 30 & 15.2 \\
\hline $3-5$ & 33 & 16.8 \\
\hline $6-8$ & 29 & 14.7 \\
\hline $9-11$ & 19 & 9.6 \\
\hline$\geq 12$ & 75 & 38.1 \\
\hline \multicolumn{3}{|l|}{ District } \\
\hline Huairou District & 51 & 25.9 \\
\hline Miyun District & 48 & 24.4 \\
\hline
\end{tabular}




\begin{tabular}{|lll|} 
Daxing district & 47 & 23.8 \\
\hline Mentougou District & 51 & 25.9 \\
\hline
\end{tabular}

A total of 36 family doctors were included in this in-depth individual interview. The youngest was 28 years old and the oldest was 56 years old. The average age of these family doctors was $39.36 \pm 6.74$ years. Among the 36 family doctors, the shortest working time was 1 year and the longest was 36 years. The average working time of these family doctors was $12.9 \pm 8.2$ years. The professional and technical titles of family doctors account for $5.6 \%$ of the overall ranks, the division accounted for $27.8 \%$ of the total, the intermediate accounted for $36.1 \%, 10$ deputy chief physicians, accounting for $27.8 \%$ of the total, and 1 chief physician, 1 proportion $2.8 \%$.

\section{The cognition of both parties to the contract service system of family doctors}

The self-assessment status of both parties' cognition of the family doctor contracting service system shows that $163(80.7 \%)$ family doctor team medical staff and $68(34.5 \%)$ contracted residents suggested they have higher awareness of the family doctor contracting service system (Learn more and much). 5 (2.5\%) family doctor team medical staff and 31 (15.7\%) contracted residents showed little understanding. Eleven (5.6\%) of the residents who signed up said they did not know anything about the system(see table 3 for details). The channels for residents to understand the contract service system of family doctors are mainly through the publicity of community medical staff, introduction of rural doctors and TV publicity.

Table3 Degree of understanding about the contracting services of family doctors by both parties

\begin{tabular}{|lllll|}
\hline Degree of understanding & \multicolumn{3}{c|}{ Family doctors } & \multicolumn{2}{c|}{ Contracted residents } \\
\cline { 2 - 5 } & $\mathrm{n}$ & $\%$ & $\mathrm{n}$ & $\%$ \\
\hline Know a lot & 74 & 36.6 & 20 & 10.1 \\
\hline To know more & $\mathbf{8 9}$ & $\mathbf{4 4 . 1}$ & 48 & 24.4 \\
\hline General & 34 & 16.8 & $\mathbf{8 7}$ & $\mathbf{4 4 . 2}$ \\
\hline Know little & 5 & 2.5 & 31 & 15.7 \\
\hline Have no idea & 0 & 0.0 & 11 & 5.6 \\
\hline Sum & 202 & 100.0 & 197 & 100.0 \\
\hline
\end{tabular}

\section{The attribute cognition and contract consciousness of both parties to the doctor-patient relationship}

Regarding the cognition of the medical staff of the family doctor team on the relationship between the contracted residents and themselves, $50.5 \%$ of the medical staff of the family doctor team stated that they had a diagnosis and treatment relationship with the contracted residents, $31.2 \%$ said that they had a trust relationship, $17.3 \%$ of the family doctors said to propose a relationship, only a few $(1.0 \%$ of the medical staff of the family doctor team) consider the contracting parties to be an economic relationship. 
As shown in table 4, the residents who signed the contract sugguested that a large percentage of medical staff performed better $(46.2 \%)$ and very good $(28.9 \%)$. Moreover, they were more proactive $(46.7 \%$ of the family doctor team medical staff were more active, $36.0 \%$ Medical staff are very proactive).

Table 4 The attribute cognition and contract consciousness of both parties to the doctor-patient relationship

\begin{tabular}{|lllll|}
\hline Variable & \multicolumn{3}{l}{ Family doctors } & \multicolumn{2}{l|}{ Contracted residents } \\
\cline { 2 - 5 } & $\mathrm{n}$ & $\%$ & $\mathrm{n}$ & $\%$ \\
\hline Clinical relationship & 102 & 50.5 & 134 & 68.0 \\
\hline Fiduciary relationship & 63 & 31.2 & 26 & 13.2 \\
\hline Pseudo-kinship & 35 & 17.3 & 34 & 17.3 \\
\hline Economic relationship & 2 & 1.0 & 3 & 1.5 \\
\hline Mutual assessment of performance & & & & \\
\hline Not fulfilled & 1 & 0.5 & 1 & 0.5 \\
\hline Less to perform & 8 & 4.1 & 9 & 4.5 \\
\hline General & 40 & 20.3 & 66 & 32.6 \\
\hline More fulfilling & 91 & 46.2 & 100 & 49.5 \\
\hline To fulfill & 57 & 28.9 & 26 & 12.9 \\
\hline Not at all & 2 & 1.0 & 29 & 14.4 \\
\hline Not very active & 7 & 3.6 & 56 & 27.7 \\
\hline General & 25 & 12.7 & 80 & 39.6 \\
\hline More active & 92 & 46.7 & 33 & 16.3 \\
\hline Very proactive & 71 & 36.0 & 4 & 2.0 \\
\hline
\end{tabular}

From the perspective of residents. $68.0 \%$ of the residents signing up had a diagnosis and treatment bond with the contracted doctors. $1.5 \%$ of the signing ups considered it an economic relationship. The medical staff from the family doctor team said that residents performed the contract well, $49.5 \%$ of residents who signed contracts fulfilled more. $12.9 \%$ of the contracted residents fully fulfilled the contract. However, in terms of the initiative of implementing the contract, more residents are not active enough, only $16.3 \%$ of the residents are active, and $2.0 \%$ of the residents are proactive.

In the personal in-depth interviews with the medical staff of the family doctor team, the medical staff stated that the medical staff of the family doctor team performed well $(61.1 \%)$, but the compliance of the residents who signed the contract was not high (41.7\%). For example, in the interview, a medical staff 
member of Miaofengshan community health service center in Mentougou District said, "The performance of medical staff is quite good. Our community health service center has been conducting family medicine for several years. Everyone slowly understands this model and recognizes it. The situation is still good, and we provide preferential policies to contracted residents, give priority to service contracted patients, regularly invite experts to give lectures, free consultations, and call the contracted residents to inform.Said a medical worker at Taishitun community health service center in Miyun District. "Residents' performance is relatively poor, because their educational levels are uneven. "You might make an appointment with him in the morning, he'll come in the afternoon. They are often not punctual."

\section{Residents' system of contracting services to family doctors and interpersonal trust from the perspective of both parties}

The questionnaire survey shows the residents of the family doctor team from the perspective of medical staff trust the system and medical staff generally lower than the degree of trust from the perspective of contracted residents. From the perspective of resident, the degree of trust in the family doctor contract service system and the moral trust in the medical staff of the family doctor team are both over $80 \%$ (including higher and higher trust) and $79.2 \%$ in their abilities. From the perspective of family doctor team medical staff, contracted residents have a low trust in the system of contracted services of family doctors. Only 20.8 percent of medical workers said that residents who signed up had a high trust in the system. Among them, $68.6 \%$ and $80.2 \%$ of the contracted residents have trust in the ability and ethics of the medical staff of the family doctor team respectively (including higher and higher trust).

Table5 The system and interpersonal trust of residents to the contracted services of family doctors from the perspective of contracting parties 


\begin{tabular}{|c|c|c|c|c|}
\hline \multirow[t]{2}{*}{ Variable } & \multicolumn{2}{|c|}{ Perspective of Family doctors } & \multicolumn{2}{|c|}{ Perspective of contracted residents } \\
\hline & $\mathbf{n}$ & $\%$ & $\mathbf{n}$ & $\%$ \\
\hline \multicolumn{5}{|c|}{ System of trust } \\
\hline Very low & 10 & 5.0 & 0 & 0.0 \\
\hline The lower & 32 & 15.8 & 4 & 2.0 \\
\hline General & 118 & 58.4 & 34 & 17.3 \\
\hline Higher & 39 & 19.3 & 85 & 43.1 \\
\hline Very high & 3 & 1.5 & 74 & 37.6 \\
\hline \multicolumn{5}{|c|}{ Competence trust } \\
\hline Very low & 1 & 0.5 & 1 & 0.5 \\
\hline The lower & 7 & 3.5 & 2 & 1.0 \\
\hline General & 55 & 27.2 & 38 & 19.3 \\
\hline Higher & 127 & 62.7 & 91 & 46.2 \\
\hline Very high & 12 & 5.9 & 65 & 33.0 \\
\hline \multicolumn{5}{|c|}{ Moral trust } \\
\hline Very low & 1 & 0.5 & 2 & 1.0 \\
\hline The lower & 0 & 0.0 & 1 & 0.5 \\
\hline General & 39 & 19.3 & 19 & 9.6 \\
\hline Higher & 113 & 55.9 & 83 & 42.1 \\
\hline Very high & 49 & 24.3 & 92 & 46.7 \\
\hline
\end{tabular}

During the interview, $50 \%$ of the family doctors said that the residents who signed the contract had low trust in the system of family doctor signing service. For example, a medical staff member of the Bohai Community Health Service Center in Huairou District said, "Residents don't have a deep understanding of the contract service system of family doctors. On a trust scale, it's 60 out of 100, let alone trust." On the issue of whether the trust of contracted residents in the medical staff of the family doctor service team is based on technical level or ethics. More than one-third of medical staff (38.0\%) said residents' trust in themselves was based more on moral character. Because residents at the grassroots level have sufficient time to communicate with doctors. "Ethical conduct is more focused," said a medical worker at Taishitun community health service center in Miyun District. "Technical deficiencies can be compensated with good moral conduct and service attitude, but if the moral conduct is not good, no amount of technology can make up for bad morals." 


\section{The continuing willingness of both parties to sign}

Among 202 family doctors surveyed, 8 (4.0\%) were unwilling (including "very unwilling" and "relatively unwilling") to maintain a long-term and stable contractual service relationship with contracted residents, 57 (28.2\%) were in general, and 137 (67.9\%) were willing (including "relatively willing" and "very willing"). Among the 197 contracted residents who involved in the questionnaire survey, 7 (3.5\%) are not willing to (including "very unwilling" and "relatively unwilling") keep long-term stable contractual service relationship with contracted doctors, 16 (8.1\%) were in general, and 174 (88.3\%) are willing (including "relatively willing" and "very willing"). Further analysis revealed there was no statistically significance in the difference between the two parties to the question. The willingness of contracted residents to uphold a long-term and stable contractual service relationship with family with family doctors is significantly higher than that of family doctors. See table 6 for details.

Table6 The willingness of both parties to maintain a long-term stable contractual service relationship

\begin{tabular}{|lllll|}
\hline Degree of willingness & \multicolumn{2}{c|}{ Family doctor } & \multicolumn{2}{c|}{ Contracted residents } \\
\cline { 2 - 6 } & $\mathrm{n}$ & $\%$ & $\mathrm{n}$ & $\%$ \\
Very unwilling & 1 & 0.5 & 1 & 0.5 \\
\hline Relatively unwilling & 7 & 3.5 & 6 & 3.0 \\
General & 57 & 28.2 & 16 & 8.1 \\
\hline Relatively willing & $\mathbf{8 8}$ & $\mathbf{4 3 . 6}$ & 77 & 39.1 \\
\hline Very willing & 49 & 24.3 & $\mathbf{9 7}$ & $\mathbf{4 9 . 2}$ \\
\hline Sum & 202 & 100.0 & 197 & 100.0 \\
\hline
\end{tabular}

\section{Discussion}

\section{Analysis of problems existing in the contract services of family doctors in suburban areas of Beijing}

First, in the process of family doctor contracting service, the family doctor service team should sign an agreement with the serving family (residents) under the principles of full notification, voluntary contracting, free choice and standardized service and establish a relatively stable contract service relationship with them [10] . However, according to the field investigation of this research group, the current method of signing services for family doctors in suburbs of Beijing is to sign by slicing. Therefore, the residents' free choice has not been implemented. The slicing contract is based on the consideration that the family doctor service team is understaffed and easy to manage, but it is difficult to achieve the expected results during the implementation process. The signing autonomy will have a great impact on the performance situation and enthusiasm of the signing residents in the later period [11]. On the one hand, involuntary choices make it difficult for contracted residents to actively understand and seek health 
services [12]. On the other hand, the non-competitive contracting method will also limit the quality of services provided by the medical staff of the family doctor's contracted service team[13]. Therefore, how to maximize the autonomy of contracted residents under the premise of guaranteeing the management effect and performance is still an important issue to be considered by current family doctor contracting services.

Second, the change of the health-seeking behavior of the contracted residents can be divided into three continuous processes: knowledge acquisition, belief generation and behavior formation. To achieve the ultimate goal of the performance it must be based on cognitive ability [14 16]. At present, contracted residents have insufficient understanding of the contract service system of family doctors, it will greatly affect their health seeking behavior[17]. According to the survey results, there are still residents who do not understand the family doctor signing system (5.6\%), which is closely related to the cognitive ability of residents. $33.5 \%$ of the residents interviewed this time have a primary school education or below, $5.6 \%$ of the resident respondents are over 75 years old. And education and seniority are important reasons affecting residents'cognition [18]. At the same time, the medical staff of the family doctor team do not have a deep understanding of the family doctor contracting service system. The World Health Organization stated primary health care is the backbone of the health system [19]. Family doctors, as practitioners of the family doctor contracted service system and the gatekeeper of residents' health, have not reached the expected degree to understand the family doctor contract service system. $2.5 \%$ of the medical staff said they had little understanding of the contracted service system of family doctors, and $16.8 \%$ of the medical staff self-assessed they had a general understanding of it.

There is a great gap between the suburban and the urban to promote and conduct family doctor contracting services. However, the signing rate of contracting services of family doctors by Beijing municipal health administration departments should be unified in all districts. The workload and pressure of subscribing to family doctors in rural areas has been increased, and the number and ability of suburban health personnel is inadequate. Under this situation, it is difficult for family doctors to provide high-quality family doctor contracting services.

\section{The contract performance and trust status of both parties of family doctors in the suburbs of Beijing}

According to the results of questionnaire survey and individual interview, the medical staff of the family doctor team have a strong sense of compliance, and good performance and initiative. The residents who sign the contract have a better performance, but have less compliance. Thus $\$ in addition to providing basic medical and health services and contract services, the medical staff of the family doctor team should also supervise the contracted residents fulfill their contracts in time. It is found in the survey that $44.7 \%$ of the respondents are close to the community health service center (less than 15 minutes on foot), and $38.1 \%$ of the contracted residents have a great demand for medical treatment (more than 12 times of medical treatment in the community health service center last year). As the traffic in the suburbs is relatively inconvenient, it has a greater impact on the enthusiasm of residents who sign contracts and fulfill the contract with relatively long distance and low demand for medical treatment. Overall, the 
consciousness of contracted residents is not strong, the signing of the family doctor's contracted service agreement is difficult to promote compliance awareness and behavior.

The cognition of the attributes of the two contracting parties shows that although most of the contracting parties said that the relationship between them was a diagnosis and treatment relationship, more than one-third of the residents considered it to be a trust and intended family relationship. Nearly half of the medical staff is expressed as the trust relationship and intended family relationship. It can be seen that the family doctor contracted service system transforms general medical staffs into family doctors, which makes the trust model of doctor-patient relationship in community health service institutions gradually change from the acquaintance society into everything bound by rule.[20].

In 1980, Olive proposed Expectation Disconfirmation Theory, which described the numerical measurement of fitting degree between actual observation result $(P)$ and theoretical expectation result (E). When $P>E$, the actual observation results are higher than expected, and consumers are satisfied [21]. Because residents have a little knowledge to the family doctor contracting service system, they have low expectation and high trust to the medical technology in the community health service institutions. From the perspective of the medical staff in the family doctor team, the trust of residents in the contracted service system of family doctors is underestimated. Then, the positioning of community health service institutions is in conflict with the Chinese residents' concept of "no medical treatment for minor diseases, specialists for serious diseases",which leads to the demand for contracted residents' medical and health services in community health service institutions as community medicine and referrals. In this process, the space for interpersonal trust interaction between the contracted residents and the family doctor is limited, which has yet to reach the trust level.

Residents of contracted residents have a higher willingness to continue contracting than medical staff of the family doctor team. The Contracted residents are the main health beneficiaries as the contracted service objects of family doctors. Because the current contracted services are free and the duties of the contracted residents are not clear, especially the relevant restrictive measures for non-performance of duties are not mentioned. The contracted residents do not need to pay for financial violations and legal costs, Lacking of moral restraint, residents pay far less than the return, so they have a higher willingness to sign a contract. Family doctor team medical personnel are the most direct practitioners of family doctor contracting services. They are the gatekeepers for the health of contracted residents .More energy and time should be devoted to the contracting service of family doctors. If the medical staff fails to meet the requirements on the quantity and quality of the contract, their performance appraisal will be reflected firstly, then this will also affect the evaluation of their working ability by the contracted residents and their superiors. At this time, the problem of the imbalance between efforts and returns has generated based on environmental reasons (imbalance between pay and return) and personal causes (excessive responsibility) [22]. Literature studies show that family doctors' team medical staff have a low sense of organizational fairness [23]. Medical staff may take actions to reduce their workload, and quality of work life to relieve this injustice [24-25]. 


\section{Countermeasures and Suggestions on the sustainable development of family doctor contract service system}

Both the government and family doctors should fully respect the signing autonomy of residents. Respect for the principle of autonomy fundamentally reflects and protects the health rights and interests of patients, which is an important content to reflect the life value and personal dignity of patients [26]. As a specific idea of doctor-patient relationship and ethics, respect for patients' independent choice first underlines patients' sense of autonomy, which is the forerunner of behavior [27]. It is a prerequisite to provide contract services for family doctors and guide residents to sign contracts on their own initiative. In order to facilitate management, in 2016, the medical reform office of the state council issued the notice on the issuance and promotion of guiding opinions on contracting services for family doctors, which mentioned that "according to the service radius and service population, the contracted service responsibility area should be reasonably divided" [28]. This part of the content is understood by some areas as dicing-type signing. That is, a village can all sign the same family doctor team. In fact, this contract service is difficult to guarantee respect for the autonomy of residents in signing contracts. Therefore, relevant government departments should take a full consideration to the principle of respect for autonomy in policy-making, and strictly define the specific methods for family doctors to sign services.

Residents shall strengthen their awareness and initiative to fulfill their duties, and the cost of breach should be clearly stipulated in the agreement. For example, free physical examination, appointment for medical treatment and referral services are no longer provided for contracted residents without affecting their health. In this way, we can restrain the behavior of contract residents and improve the effective utilization of medical resources. At the same time, the active contracted residents will gain incentives, such as free physical examination, referral and interrogation of the experts. Foreign experience can also be used for reasonably defining and standardizing the content of family doctors' contracted service items [29-31], reducing the non-medical workload of family doctors' medical staff [32], narrowing the gap between supply and demand [33], and improve the sense of gain of both doctors and patients.

According to the different geographical topography and traffic conditions in Beijing, especially the difference between the suburbs and the urban. The contents and methods of services provided by family doctors in contract services should be reasonably planned in line with the local conditions. The number and scope of contracted services should be reasonably determined based on the population composition, service radius and distribution of medical resources. Related medical institutions should relieve family doctor team medical staff from working overload. At the same time, more preferential policies should be adopted to increase the attractiveness of family doctor positions to medical college graduates in terms of salary level, working environment and promotion mechanism. In addition, each family doctor service team is equipped with an assistant position to assist the team in non-medical work such as publicity of family doctor contract service, record entry management and supervision of performance. 
The government and relevant departments should innovate the publicity of family doctor contract services through multiple channels. In terms of propaganda, they should not confuse the content of family doctor service and the content of other work in community health. It is necessary to highlight service main body and expand the contracted residents' konwledge to the contracted service of family doctors. In the form of publicity, according to the characteristics of contract groups, they should pay attention to direct publicity of language and video transmission mode. In the selection of publicity space, it is necessary to break through the geographical limitations of community health service institutions and the community should be used for publicity in order to achieve the best publicity effect.

\section{Conclusions}

This survey and interviews will help the industry understand the problems existing in imposing family doctor contracting services with Chinese characteristics. Studies have shown that the current contract service mode of Beijing family doctors has, to a certain extent, hindered residents' trust in the contract service team of family doctors and their willingness to continue to sign. How to respect the autonomy of contracted residents is a key ethical issue needs to be considered in forming China's medical and health service system. There is still a long way to improve the performance and enthusiasm of the contracting parties and heighten the trust in the family doctor contract service system way to go. The government and relevant departments must immediately take feasible measures to reduce the ambiguity of policy terms and ensure the implementation of two-way incentives for both parties.

This research adopts a descriptive research method to describe the relevant performance and trust status of both parties. We still have not determined the causal relationship just through cross-sectional investigations. It may be difficult to be objective, despite efforts to avoid conclusions that are too subjective. In the future, it is still necessary to update and supplement relevant data through continuous and in-depth investigation, so as to provide more decision-making references for improving the operation recommendations of family doctor contract service model.

\section{Declarations}

\section{Acknowledgements}

This study was conducted with the support of the Beijing Social Science Foundation.

\section{Author details}

${ }^{134}$ School of Medical Humanities, Capital Medical University, Beijing 100069, China. ${ }^{2}$ Xiluoyuan Community Health Service Center, Fengtai District, Beijing 100077, China. ${ }^{5}$ Peking University International Hospital, Beijing 102206, China. ${ }^{6}$ Guangwai Community Health Service Center, Xicheng District, Beijing, 100055,China. ${ }^{7}$ Liulimiao Community Health Service Center, Huairou District, Beijing 101409, China. 


\section{Authors' contributions}

YCP participated in the design of the study and drafted the manuscript. JJZparticipated in the design of the study and helped to revise the manuscript. ZZZ participated in the revision and English polishing of the manuscript. RYZ participated in the survey and collated the data.LDL and ZW conceived the study and helped to draft the manuscript.JJC assisted in the field investigation.All authors read and approved the final manuscript.

\section{Competing interests}

All authors declare that they have no competing interests.

\section{References}

[1] Zhang rongrong, Li xiaochun. Analysis of problems and countermeasures in family doctor system service in China [J].China Journal of Pharmaceutical economics, 2008,13(06):105-108.

[2] The CPC central committee and the state council. Opinions on deepening reform of the medical and health care system [Z]. 2009-03-17.

[3] Xiao feng, Wu xiaoling, Zhao deyu. Family doctor system: new exploration of basic medical and health service model [J]. China Market Region\&City,2012(29):84-90.

[4] Beijing community health service management center. Beijing community health routine data monitoring statistical analysis report 2015 [R].2016-05.

[5] Beijing community health service management center. Beijing community health routine data monitoring statistical analysis report 2017 [R].2018-06.

[6] Beijing community health service management center. Beijing community health routine data monitoring statistical analysis report 2018 [R].2019-10.

[7]Zhao shuai-ran, Li na, Liu ya-lan. A study on the rationality of spatial distribution of medical resources in Beijing [J]. Contemporary medicine,2018(2):22-25.

[8]National health and health commission grassroots health and health department.Guidance on standardizing the management of contract services for family doctors [Z].2018-10-08.

[9] Huge J, Mukherjee N. The nominal group technique in ecology \& conservation: Application and challenges [J]. Methods in Ecology \& Evolution, 2018,9(1).

[10] Research on operating mechanism of family medical service - based on the implementation of xisanqi in haidian district, Beijing [D]. Nanchang: nanchang university,2013. 
[11]Alison Pilnick,Olga Zayts. Advice, authority and autonomy in shared decision-making in antenatal screening: the importance of context [J]. Sociology of Health \&amp; Illness, 2016,38(3).

[12]Kim P H , Harmon D J . Justifying one's transgressions: how rationalizations based on equity, equality, and need affect trust after its violation.[J]. Journal of Experimental Psychology Applied, 2014, 20(4):36579 .

[13]Geoffrey K. Turnbull, Jonathan Dombrow. Spatial Competition and Shopping Externalities: Evidence from the Housing Market[J]. 32(4):391-408.

[14]Cleary A, Dowling M.Knowledge and attitudes of mental health professionals in Ireland to the concept of recovery in mental health:a questionnaire survey[J].J Psychiatr Ment Health Nurs, 2009, 16 (6) :539545 .

[15] Watters AL, Stabulas-Savage J, Toppin JD, et al.Incorporating experiential learning techniques to improve self-efficacy in clinical special care dentistry education[J].J Dent Educ, 2015, 79 (9):1016-1023.

[16] Aflalo E, Dichtiar R, Zusman SP, et al.The association between health attitudes and behaviors and oral-health-related practices[J].Quintessence Int (Berl) , 2018, 49 (2) :153-162.

[17]Mokhtari H, Davarpanah M R , Dayyani M H, et al. Students' need for cognition affects their information seeking behavior[J]. New Library World, 2013, 114(11/12):542-549(8).

[18]Deary I J , Corley J , Gow A J , et al. Age-associated cognitive decline[J]. British Medical Bulletin, 2009, 92(1):135-152.

[19]Cubaka Vincent K,Dyck Clayton,Dawe Russell,Alghalyini Baraa,Whalen-Browne Molly,Cejas Gabriel,Gibson Christine. A global picture of family medicine: the view from a WONCA Storybooth.[J]. BMC family practice,2019,20(1).

[20] Zhai xuewei. Social mobility and gao xiaoou's trust: also on the relationship strength and migrant workers' job-seeking strategies [J]. Sociological research,2003囚1囚:1-11.

[21] Richard L Oliver.A cognitive model of the antecedents and consequences of satisfaction decisions[J].Journal of Marketing Research, 1980, 17 (4) :460-469.

[22]SIEGRIST J.Adverse health effects of high-effort/low-reward conditions[J].J Occup Health Psychol, 1996,1 (1) :27-41.

[23]COLQUITT JA, CONLON DE, WESSON MJ, et al.Justice at the millennium:a meta-analytic review of 25 years of organizationaljustice research[J].J Appl Psychol, 2001, 86 (3) :425-445.

[24]Ahmed W , Kiyani A, Hashmi S H. The Study on Organizational Cynicism, Organizational Injustice \& Breach of Psychological Contract as the Determinants of Deviant Work Behavior[J]. Social Science 
Electronic Publishing, 2013, 140(2):145-154.

[25]EMBRIACO N, AZOULAY E, BARRAU K, et al.High level ofburnout in intensivists:prevalence and associated factors[J].Am J Respir Crit Care Med, 2007, 175 (7) :686-692.

[26] Beecham, James chiu, Li lun et al. Principles of ethics in life medicine [M]. Beijing: Peking University press,2014.

[27] Zheng wenqing, zhou hongju, Ed. Introduction to modern medical ethics [M].2012,38-39.

[28] Medical reform office of the state council.Notice on the issuance and promotion of guiding opinions on contracting services of family doctors [Z].2016-05-25.

[29]NHC Confederation and British Medical Association and British Medical Association. Investing in GP :The new GMS contract[R].London :British Medical Association,2003.

[30]Cornino E ,Sullivan E, Harria E.et al. A community-based health service census: describing the client base [J].Aust J Prim Health Interchange,2000,6(2):63-67.

[31] Zhang dongying, Zheng chan jiao, Huang xiang, et al. SWOT analysis of family doctor services in urban and rural areas of guangdong province [J]. Chinese general practice,2015 $₫ 05 \llbracket 689-691+705.0 \square$

[32] Han yanni, Sun jianli. Analysis on current situation and influencing factors of family doctor contract service - a case study of jiading district, Shanghai [J]. Assets and finance of administrative undertakings, $2015 \otimes 10: 37-38+25$.

[33] Zhang dandan, Wang tong, Jin guanghui, et al. Status quo of family physician services in suburban areas and counties of Beijing: panel interview of general practitioners [J]. Chinese general practice,2016,09:1425-1428.

\section{Supplementary Files}

This is a list of supplementary files associated with this preprint. Click to download.

- checklist.docx 